\title{
The Association of 5-HTTLPR XLL Genotype with Higher Cortisol Levels in African Americans
}

\author{
Carmen L. Contreras-Sesvold, ${ }^{1,2}$ Preetha Abraham, ${ }^{1}$ Joseph M. Devaney, ${ }^{3}$ \\ Brennan T. Harmon, ${ }^{3}$ and Patricia A. Deuster ${ }^{1}$ \\ ${ }^{1}$ Human Performance Laboratory, Uniformed Service University of the Health Sciences, Bethesda, MD 20814, USA \\ ${ }^{2}$ Naval Medical Research Center, Silver Spring, MD 20910, USA \\ ${ }^{3}$ Children's National Medical Center, Washington Hospital Center, Washington, DC 20010, USA
}

Correspondence should be addressed to Carmen L. Contreras-Sesvold; carmen.l.contreras-sesvold.ctr@mail.mil

Received 29 August 2014; Revised 15 December 2014; Accepted 18 December 2014

Academic Editor: Kei Kamide

Copyright (c) 2015 Carmen L. Contreras-Sesvold et al. This is an open access article distributed under the Creative Commons Attribution License, which permits unrestricted use, distribution, and reproduction in any medium, provided the original work is properly cited.

\begin{abstract}
Genetic variants of the human serotonin transporter (SERT) may contribute to HPA axis dysregulation. SERT has two promoter region polymorphisms (5-HTTLPR: VNTR and SNP: rs25531), which may alter levels of SERT protein and its function. Combining these polymorphisms creates a functional polymorphism (FN) which may modulate mRNA expression. This study examines the relationship between these genetic variants and morning and evening salivary samples of both cortisol and dehydroepiandrosterone sulfate (DHEAS) concentrations in 269 African American (AA) adults. Resultant allele frequencies for the VNTR, SNP, and FN genotypes were $70 \% \mathrm{~L}$ ( $2 \%$ XLL), $84 \%$ A, and 54\% LA (2\% XLLA), respectively. The XLL genotype was associated with significantly higher concentrations of cortisol $(\sim 3 \mathrm{X})$ and DHEAS $(\sim 2 \mathrm{X})$ for both VNTR and FN polymorphisms. No significant differences were found for SNP genotypes. Conclusions were that persons with VNTR and FN XLL polymorphisms had significantly higher cortisol and DHEAS concentrations than other genotypes. AAs also appear to have a higher frequency of the rare XL allele than Caucasians. Whether the XLL genotype predisposes AAs to greater health challenges will require further research to determine the implications of these findings.
\end{abstract}

\section{Introduction}

The serotonergic system is a component of the central nervous system associated with differential hypothalamicpituitary-adrenal (HPA) axis responses to stress [1-3]. The serotonergic system can indirectly modulate the secretion of cortisol and alter feedback regulation of cortisol and the HPA axis [4-7]. The HPA axis has a well-characterized response to stress and strong diurnal rhythm $[8,9]$. Under normal circumstances, cortisol levels are high upon waking and reach a peak about 30 to 40 minutes after waking and steadily decline throughout the day to reach a nadir around midnight $[8,10]$. Diurnal pattern deviations have been correlated with negative health and psychological outcomes [11-13]. Similar diurnal patterns have also been reported for dehydroepiandrosterone sulfate (DHEAS) [14, 15]. Moreover, abnormal concentrations of cortisol and DHEAS have been linked to HPA axis dysfunction [16-19].

The SLC6A4 gene codes for the human serotonin transporter (SERT; NCBI Gene ID: 6532). SERT controls the rate of serotonin reuptake from the synaptic cleft [20]. This gene has specific polymorphic changes within the promoter region, with one being the insertion of a variable number tandem repeat (VNTR) within its promoter region (5HTTLPR) [21]. The alleles of this polymorphism are classified as short (S) for those missing the insertion, long (L) for those with the insertion, and extralong (XL) for those with an additional insertion. This particular allelic categorization appears to influence the amount of SERT mRNA expression and serotonin neurotransmission [22]. Moreover, the LL diplotype is associated with higher transcriptional activity, binding efficiency, and serotonin reuptake than the LS and SS 


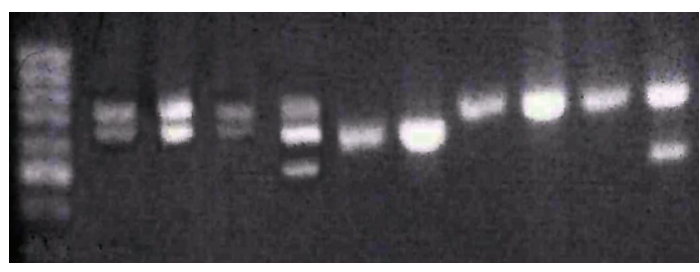

(a)

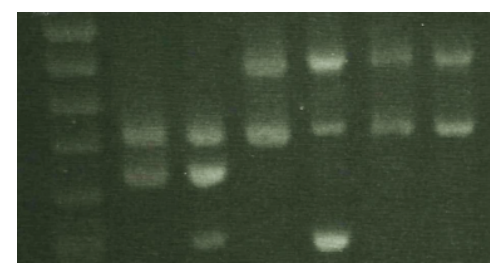

(b)

FIgURE 1: (a) PCRs of common L and S VNTRs with subsequent digestions for the A and G alleles in the following lane. Lane 1100 bp DNA ladder, Lane 2 PCR LS Diplotype, Lane 3 Digestion $\mathrm{L}_{\mathrm{A}} \mathrm{S}+$, Lane 4 PCR LS Diplotype, Lane 5 Digestion $\mathrm{L}_{\mathrm{G}} \mathrm{S}+$, Lane 6 PCR SS Diplotype, Lane 7 Digestion $\mathrm{S}+\mathrm{S}+$, Lane 8 PCR LL Diplotype, Lane 9 Digestion $\mathrm{L}_{\mathrm{A}} \mathrm{L}_{\mathrm{A}}$, Lane 10 PCR LL Diplotype, and Lane 11 Digestion $\mathrm{L}_{\mathrm{A}} \mathrm{L}_{\mathrm{G}}$. (b) PCRs of the Mutant alleles (with LS for reference) with subsequent digestions for the A and G alleles in the following lane. Lane $11 \mathrm{Kbp}$ DNA ladder, Lane 2 PCR LS Diplotype, Lane 3 Digestion $\mathrm{L}_{\mathrm{G}} \mathrm{S}+$, Lane 4 PCR XLL Diplotype, Lane 5 Digestion $\mathrm{XLL}_{\mathrm{G}}$, Lane 6 PCR XLL Diplotype, and Lane $7 \mathrm{XLL}_{\mathrm{A}}$ digestion.

diplotypes, resulting in more efficient clearing of serotonin from the synaptic cleft [23]. However, investigations of these polymorphisms with physiological outcomes have mixed results [24]. The inconsistent results may in part be explained by the identification of a single nucleotide polymorphism, an adenine to guanine substitution (SNP; rs25531), within the previously mentioned polymorphic region [25]. Recently these two genetic variants have been combined to create new haplotypes designated $\mathrm{L}_{\mathrm{A}}, \mathrm{L}_{\mathrm{G}}, \mathrm{S}_{\mathrm{A}}$, and $\mathrm{S}_{\mathrm{G}}$. Molecular characterization of $\mathrm{L}_{\mathrm{A}}, \mathrm{L}_{\mathrm{G}}, \mathrm{S}_{\mathrm{A}}$, and $\mathrm{S}_{\mathrm{G}}$ variants in cell culture, by $\mathrm{Hu}$ et al. [24], clearly demonstrated that the $\mathrm{L}_{\mathrm{A}}$ haplotype is associated with approximately twice the amount of mRNA expression compared to $S_{A}$. Further, work by this team identified that the A to $G$ substitution resulted in an AP2-binding site on the L allele which acts as a transcriptional suppressor. This group also reported that the mRNA expression for $\mathrm{S}_{\mathrm{A}}, \mathrm{L}_{\mathrm{G}}$, and $\mathrm{S}_{\mathrm{G}}$ haplotypes appears to be nearly equivalent [24], and they therefore designated all three variants as S+. Together these haplotypes create functional diplotypes (FN): $\mathrm{L}_{\mathrm{A}} \mathrm{L}_{\mathrm{A}}, \mathrm{L}_{\mathrm{A}} \mathrm{S}+$, and $\mathrm{S}+\mathrm{S}+$ which are based on transcriptional regulation.

The objective of this study was to evaluate how SERT 5HTTLPR variants affect HPA axis function as measured by cortisol levels. In particular, we hypothesized that the $\mathrm{S}+\mathrm{S}+$ diplotype would be associated with higher morning cortisol levels as compared to the other diplotypes. Specifically, we sought to determine whether levels of morning cortisol (AM-CORT), evening cortisol (PM-CORT), and mean cortisol (M-CORT), as well as diurnal cortisol variation (DICORT), differed by genotype. Also, we explored differences in morning (AM-DHEAS) and evening (PM-DHEAS) dehydroepiandrosterone sulfate and mean DHEAS (M-DHEAS) by genotype. Further, as the XL allele was found in this population, we documented the association between the XL variant, cortisol, and DHEAS.

\section{Methods}

2.1. Participants. Participants included men and women between 18 and 60 years old of African descent (AA) who were recruited through public advertisements, announcements, and local churches in the Greater Washington DC area. Criteria for exclusion were pregnancy or the use of steroidal medications including prednisone. Subjects arrived at approximately $8 \mathrm{AM}$ in the fasted condition at the Human Performance Laboratory at Uniformed Services University of the Health Sciences (HPL) for sample and data collection. The study was approved by the Institutional Review Board of the Uniformed Services University of the Health Sciences. Informed consent was obtained from all participants prior to the beginning of the study.

2.2. DNA Extraction and Genotyping. Blood samples for DNA were collected for analysis of selected SNPs as part of a larger study at the HPL research facility. Genomic DNA was successfully extracted from 254 participants as previously described [26]. Portions of DNA stock solutions were subsequently diluted to $25 \mathrm{ng} / \mu \mathrm{L}$ to create standardized working solutions.

Genotyping for the 5-HTTLPR VNTR and rs25531 SNP within the amplicon was performed by polymerase chain reaction (PCR) using $25 \mathrm{ng}$ genomic DNA, 300 nmoles of each primer, forward $5^{\prime}$ TCCTCCGCTTTGGCGCCTCTT$\mathrm{CC}^{\prime}{ }^{\prime}$ and reverse $5^{\prime}$ TGGGGGTTGCAGGGGAGATCCTG3', and PCR grade water (Fisher BioReagents, Fairlawn, NJ, USA) and QIAGEN multiplex PCR master mix kit (Valencia CA, USA) as per package instructions was used because it corrects for short allele amplification bias. Thermocycler (iCycler iQ4, BioRad, Hercules, CA, USA) conditions were initial denaturation at $95^{\circ} \mathrm{C}(15 \mathrm{~min})$, followed by 40 cycles of $95^{\circ} \mathrm{C}(30 \mathrm{sec}), 60^{\circ} \mathrm{C}(90 \mathrm{sec})$, and $72^{\circ} \mathrm{C}(30 \mathrm{sec})$, ending with a final elongation step at $72^{\circ} \mathrm{C}(4 \mathrm{~min})$. All experiments were accomplished with positive controls and "no template" negative controls. This assay resulted in VNTR amplicons of $469 \mathrm{bp}$ for S allele, $512 \mathrm{bp}$ for the L allele, and $600 \mathrm{bp}$ for the $\mathrm{XL}$ allele as demonstrated in Figure 1.

Restriction fragment length polymorphisms (RFLPs) were generated by overnight digestions with HpaII (New England Biolabs, Ipswich, MA, USA) as per package instructions. Amplicons and RFLPs were visualized by electrophoresis in a $2 \%$ agarose gel and documented on a Gel Doc (BioRad). Digestion indicated the presence of the A or $G$ allele for the rs 25531 SNP with bands of $469 \mathrm{bp}$ for the $\mathrm{S}_{\mathrm{A}}, 402$ and $67 \mathrm{bp}$ for the $\mathrm{S}_{\mathrm{G}}, 512 \mathrm{bp}$ for the $\mathrm{L}_{\mathrm{A}}$, and 402 and $110 \mathrm{bp}$ for 
the $\mathrm{L}_{\mathrm{G}}$; all XL amplicons carried the A allele and were $\sim 600 \mathrm{bp}$ in size as demonstrated in Figure 1.

Genetic assays were repeated by a separate lab (Children's National Medical Center (CNMC)) blinded to previous results using previously described primers [23] with similar PCR conditions followed by a two-hour digestion for samples with L alleles with MspI (New England Biolabs) as per package instructions. The substitution of the $\mathrm{G}$ for $\mathrm{A}$ in the SNP produces an additional MspI recognition site (CCGG) on the long allele of the 5-HTTLPR PCR product. Samples with an A allele showed bands at 62,127, and 340 bps. Samples with the $\mathrm{G}$ allele had bands at $62,127,166$, and 174. Genotypes were then determined by running the digested PCR products out on a $2 \%$ agarose gel stained with ethidium bromide.

2.3. Hormone Analysis. Saliva samples for measuring cortisol and DHEAS were collected by the participants, one upon waking or by $8 \mathrm{AM}$ (AM-CORT and AM-DHEAS) and another in the evening (PM-CORT and PM-DHEAS) between 5 and $6 \mathrm{PM}$. The samples were stored at $-20^{\circ} \mathrm{C}$ until they were ready for shipment. Participants were instructed to refrain from eating or drinking 45 to 60 minutes before collection. Saliva samples were mailed to the investigators in prestamped envelopes and upon arrival stored at $-80^{\circ} \mathrm{C}$ for no longer than 1 month before analysis. Vials were processed by Diagnos-Tech Inc. (Tukwila, WA, USA) for analyses of the bioactive (free fraction) portion of saliva analyte using an enzyme immunoassay procedure; values are expressed in $\mathrm{nmol} / \mathrm{L}$.

2.4. Statistics. The Hardy-Weinberg Equilibrium (HWE) equation followed by the Chi Square test $\chi^{2}$ was used to analyze genotypes/alleles for the normal distribution and validate HWE distribution adherence. Fisher's Exact Test and $\chi^{2}$ were used to compare the allele distribution with other published studies. The categorical influences of genotype on hormone concentrations were determined by ANOVA and/or independent samples $t$-test when applicable with $95 \%$ confidence intervals. Hormone values were reported as mean \pm standard error (SE). Diurnal cortisol (DI-CORT) was calculated as the difference between AM-CORT and PMCORT, while the mean cortisol (M-CORT) was calculated as the sum of AM-CORT and PM-CORT divided by 2 for each subject. Mean DHEAS (M-DHEAS) was calculated as the sum of AM-DHEAS and PM-DHEAS divided by 2 for each subject. The level of significance was set at $P<0.05$ and trends were recognized at $P$ values between 0.05 and 0.10 . All calculations were performed using SPSS v20 software (SPSS, Inc., Chicago, IL, USA).

\section{Results}

3.1. Characteristics of the Study Population. The cohort included 269 individuals, 100 male and 169 female AA subjects. The mean weight was $86.7 \pm 23.9 \mathrm{Kg}$ (range $=42.5$ to $185 \mathrm{Kg}$ ) and mean age was $44 \pm 11$ years (range $=18$ to 60 years old).
TABLE 1: Distributions of the VNTR, SNP, and FN genotypes for the 5-HTTLPR.

\begin{tabular}{cccc}
\hline \multicolumn{2}{c}{ Genotype } & $\begin{array}{c}\text { Population } \\
\text { with genotype }\end{array}$ & $\begin{array}{c}\text { Population } \\
\text { distribution } \\
(\%)\end{array}$ \\
\hline \multirow{4}{*}{ VNTR } & XLL & 5 & 2 \\
& LL & 131 & 52 \\
& LS & 92 & 36 \\
\hline \multirow{3}{*}{ SNP } & SS & 26 & 10 \\
& AA & 178 & 70 \\
& AG & 69 & 27 \\
\multirow{4}{*}{ FN } & GG & 7 & 3 \\
& XLL & 5 & 2 \\
& $\mathrm{~L}_{\mathrm{A}} \mathrm{L}_{\mathrm{A}}$ & 74 & 29 \\
& $\mathrm{~L}_{\mathrm{A}} \mathrm{S}+$ & 126 & 50 \\
& $\mathrm{~S}+\mathrm{S}+$ & 49 & 19 \\
\hline
\end{tabular}

Genetic distribution of sample number and percent population for the 5HTTLPR VNTR, SNP, and FN genotypes.

3.2. Genetic 5-HTTLPR Distribution. Genotyping was completed for 254 subjects. The distribution of the VNTR alleles was $70 \% \mathrm{~L}, 28 \% \mathrm{~S}$, and $2 \% \mathrm{XL}$. The distribution of the SNP alleles was $84 \%$ for A and $16 \%$ for G. Both polymorphisms met Hardy-Weinberg Equilibrium (HWE) conditions (VNTR: $\chi^{2}=2.7 ; P=0.10$; rs25531 SNP: $\chi^{2}$ value of 0.01 ; $P=0.91$ ). Likewise, the FN genetic distribution was $54 \%$ for $\mathrm{L}_{\mathrm{A}}, 44 \%$ for $\mathrm{S}+$, and $2 \%$ for the XL alleles and was within HWE $\left(\chi^{2}=0.37 ; P=0.54\right)$. Genotypic distributions for the study are presented in Table 1 .

3.3. Salivary Cortisol and DHEAS by VNTR, SNP, and $F N$. Cortisol concentrations by VNTR showed that AMCORT and PM-CORT concentrations differed significantly by VNTR genotype $[F(3,224)=5.4$ and $2.62, P<$ 0.01 , resp.]. Further, the XLL AM-CORT and PM-CORT genotype had cortisol levels almost threefold that of others. This resulted in a significant difference for M-CORT levels $[F(3,224)=5.1, P<0.00]$. DI-CORT values demonstrated a trend for a greater diurnal difference $[F(3,224)=2.4$, $P=0.07]$. Those with the XLL genotype were over 2 times the total study average while LS was nearly half. In the absence of the XLL genotype, the mean DI-CORT levels increased in significance $[F(2,220)=3.3, P<0.05]$. Those with the LS genotype had a significantly smaller difference between AM-CORT and PM-CORT concentrations than the other genotypes. Table 2 shows mean salivary cortisol concentrations by genotype. DHEAS analysis demonstrated that the mean AM-DHEAS differed significantly by VNTR $[F(3,241)=4.6, P<0.01]$, and the XLL genotype had levels over two times higher than other genotypes. The M-DHEAS concentration was also significantly different $[F(3,241)=$ $3.2, P<0.05$ ] by VNTR. No significant difference was found for other genotypes in the absence of the XLL genotype $(P>0.05)$. Mean DHEAS concentrations by genotype are 
TABLE 2: Mean salivary cortisol concentrations by 5-HTTLPR genotypes.

\begin{tabular}{|c|c|c|c|c|c|}
\hline \multicolumn{2}{|c|}{ Genotype $(n)$} & AM cortisol (nmol/L) & $\mathrm{PM}$ cortisol $(\mathrm{nmol} / \mathrm{L})$ & Mean cortisol (nmol/L) & Diurnal cortisol (nmol/L) \\
\hline \multirow{4}{*}{ VNTR } & LL (117) & $11.1 \pm 0.96$ & $5.9 \pm 0.67$ & $8.5 \pm 0.70$ & $5.1 \pm 0.88$ \\
\hline & LS (84) & $10.6 \pm 1.49$ & $8.0 \pm 1.57$ & $9.3 \pm 1.44$ & $* 2.6 \pm 1.04$ \\
\hline & SS (22) & $14.3 \pm 3.13$ & $6.4 \pm 1.60$ & $10.4 \pm 2.26$ & $8.0 \pm 2.07$ \\
\hline & XLL (5) & ${ }^{*} 33.8 \pm 16.75$ & ${ }^{*} 22.8 \pm 17.26$ & ${ }^{*} 28.3 \pm 14.77$ & ${ }^{\dagger} 11.0 \pm 16.86$ \\
\hline \multirow{3}{*}{ SNP } & AA (157) & $11.1 \pm 1.12$ & $7.3 \pm 1.07$ & $9.5 \pm 1.04$ & $4.6 \pm 0.89$ \\
\hline & AG (64) & $11.8 \pm 1.30$ & $7.2 \pm 0.94$ & $9.5 \pm 0.92$ & $4.5 \pm 1.33$ \\
\hline & GG (7) & $9.4 \pm 1.36$ & $3.3 \pm 1.04$ & $6.3 \pm 0.96$ & $6.1 \pm 1.47$ \\
\hline \multirow{4}{*}{$\mathrm{FN}$} & $\mathrm{L}_{\mathrm{A}} \mathrm{L}_{\mathrm{A}}(67)$ & $10.2 \pm 1.33$ & $4.9 \pm 0.88$ & $7.5 \pm 1.00$ & $5.4 \pm 1.01$ \\
\hline & $\mathrm{L}_{\mathrm{A}} \mathrm{S}+(126)$ & $11.6 \pm 1.21$ & $8.1 \pm 1.18$ & $9.9 \pm 1.09$ & ${ }^{\dagger} 3.5 \pm 1.00$ \\
\hline & $S+S+(47)$ & $11.7 \pm 1.78$ & $5.8 \pm 1.02$ & $8.7 \pm 1.32$ & $5.9 \pm 1.21$ \\
\hline & $\mathrm{XLL}_{\mathrm{A}}(5)$ & $* 33.8 \pm 16.75$ & ${ }^{*} 22.8 \pm 17.26$ & ${ }^{*} 28.3 \pm 14.77$ & $11.0 \pm 16.86$ \\
\hline
\end{tabular}

Study concentration average of cortisol \pm SE by genotype for morning and evening. Mean cortisol is the calculated average between morning and evening cortisol for the study while diurnal cortisol is the difference between morning and evening levels. ${ }^{*}$ indicates significance at $P<0.05$; ${ }^{\dagger}$ indicates trend $P<0.10$ and $>0.05$.

TABLE 3: Mean salivary DHEAS concentrations by 5-HTTLPR genotypes.

\begin{tabular}{|c|c|c|c|c|}
\hline \multicolumn{2}{|c|}{ Genotype $(n)$} & \multirow{2}{*}{$\begin{array}{c}\text { AM DHEAS }(\mathrm{nmol} / \mathrm{L}) \\
19.9 \pm 1.35\end{array}$} & \multirow{2}{*}{$\begin{array}{c}\text { PM DHEAS }(\mathrm{nmol} / \mathrm{L}) \\
15.9 \pm 2.04\end{array}$} & \multirow{2}{*}{$\begin{array}{c}\text { Mean DHEAS }(\mathrm{nmol} / \mathrm{L}) \\
17.9 \pm 1.28\end{array}$} \\
\hline \multirow{4}{*}{ VNTR } & LL (124) & & & \\
\hline & LS (91) & $18.2 \pm 1.23$ & $16.4 \pm 1.40$ & $17.3 \pm 1.16$ \\
\hline & SS (25) & $18.6 \pm 3.31$ & $16.6 \pm 2.27$ & $17.6 \pm 2.68$ \\
\hline & XLL (5) & ${ }^{*} 42.9 \pm 14.65$ & $28.8 \pm 6.11$ & ${ }^{*} 35.8 \pm 7.79$ \\
\hline \multirow{3}{*}{ SNP } & AA (170) & $20.1 \pm 1.10$ & $17.7 \pm 1.65$ & $18.9 \pm 1.10$ \\
\hline & AG (68) & $19.4 \pm 2.02$ & $14.2 \pm 1.06$ & $16.8 \pm 1.26$ \\
\hline & GG (7) & $11.6 \pm 1.14$ & $8.1 \pm 1.18$ & $9.9 \pm 1.01$ \\
\hline \multirow{4}{*}{$\mathrm{FN}$} & $\mathrm{L}_{\mathrm{A}} \mathrm{L}_{\mathrm{A}}(67)$ & $19.8 \pm 1.56$ & $18.0 \pm 3.63$ & $18.9 \pm 2.01$ \\
\hline & $\mathrm{L}_{\mathrm{A}} \mathrm{S}+(126)$ & $19.9 \pm 1.30$ & $15.9 \pm 1.14$ & $17.9 \pm 1.04$ \\
\hline & $S+S+(47)$ & $16.2 \pm 2.00$ & $14.3 \pm 1.35$ & $15.2 \pm 1.57$ \\
\hline & $\mathrm{XLL}_{\mathrm{A}}(5)$ & ${ }^{*} 42.9 \pm 14.65$ & $28.8 \pm 6.10$ & ${ }^{* *} 35.8 \pm 7.79$ \\
\hline
\end{tabular}

Study concentration average of DHEAS \pm SE by genotype for morning and evening. Mean DHEAS is the calculated average between morning and evening DHEAS for the study. ${ }^{*}$ indicates significance at $P<0.05 .{ }^{* *}$ This is a type the significance was $P<0.01$.

presented in Table 3. Hormone concentration by SNP analysis showed no significant differences $(P>0.05)$.

Analysis by FN genotype demonstrated significant differences for AM-CORT, PM-CORT, M-CORT, AM-DHEAS, and the M-DHEAS $(P<0.01)$. The $\mathrm{XLL}_{\mathrm{A}}$ genotype had significantly higher hormone concentrations than the other three genotypes.

\section{Discussion}

The serotonin transporter (SERT), one of the primary modulators of serotonin function, has been studied with regard to anxiety, depression, obsessive-compulsive disorder, and stress reactivity [27]. In addition to the common VNTR alleles, we discovered a small subpopulation carrying the XL allele in our cohort. The XL allele appears to be more common in those of African descent than Caucasian [28]. In this study, those with the XLL genotype had threefold higher mean cortisol levels and twofold mean higher AM DHEAS levels than those with the LL, LS, or SS genotypes. These findings were also significant for the $\mathrm{FN} \mathrm{XLL}_{\mathrm{A}}$ genotype, but not for the rs25531 SNP genotypes.

We hypothesized that the SS or S+S+ variants would have lower mRNA expression and produce fewer SERT, which should increase serotonin bioavailability in comparison to the other genotypes. Thus, we expected the $\mathrm{SS} / \mathrm{S}+\mathrm{S}+$ genotypes to be associated with elevated cortisol levels. Our hypothesis was not supported by the results. However, the XLL genotype was associated with a threefold increase in cortisol and a twofold increase in DHEAS levels relative to the other genotypes. Further, the LS genotype had significantly smaller differences in AM-CORT and PM-CORT levels than the other genotypes. This flattened response was not dose dependent by genotype, as the LS and SS homozygotes show pronounced variation. A reduction in the DI-CORT variation suggests an impaired feedback regulation of cortisol and possibly the HPA axis. Further research is needed to discern this mechanism.

To our knowledge, this is the first study in which the $\mathrm{FN}$ was examined in humans with the $\mathrm{XLL}_{\mathrm{A}}$ allele. In work examining the $\mathrm{L}_{\mathrm{A}} \mathrm{L}_{\mathrm{A}}, \mathrm{L}_{\mathrm{A}} \mathrm{S}+$, and $\mathrm{S}+\mathrm{S}+\mathrm{FN}$ variants, Alexander et al. found that men with the $\mathrm{S}+\mathrm{S}+$ genotype and a significant 
history of stressful life events exhibited significantly greater elevations in cortisol levels in response to a stressor than those with the other genotypes [29]. Similarly, Wankerl and colleagues supported these findings but also found a significant sex by FN interaction. Higher cortisol levels were noted in men with the $\mathrm{S}+\mathrm{S}+$ genotype but not in women, relative to the other genotypes [3].

It is of interest that if we excluded the XLL genotype from our analyses, the SS group had slightly, elevated morning cortisol concentrations relative to the LS and LL genotypes, but it was not significant. Thus the association between the 5-HTTLPR FN and cortisol will require further research to determine the nature of these discrepancies.

The nonsignificant findings for the rs25531 SNP genotypes are similar to other studies [30] that support the suggestion that this SNP, when analyzed in the absence of the VNTR variable, may be a nonfunctional variant [24] with respect to cortisol level modulation. However our interpretation is limited since only seven people in our study were homozygous for the $G$ allele. Further investigation with a larger sample size would be required to make that determination. Our FN analysis also demonstrated that those with the $\mathrm{XLL}_{\mathrm{A}}$ genotype had significantly elevated morning and evening cortisol levels. However, the same people were in the VNTR XLL and the FN XLL $\mathrm{A}_{\mathrm{A}}$ groupings, and therefore the results were expected.

Limitations to our study include the small sample size for the XLL VNTR, GG SNP, and $\mathrm{XLL}_{\mathrm{A}}$ FN genotypes. Thus, our results need to be confirmed with a larger sample size. In addition, we did not control for age, menstrual status, mental health status, and use of medication/drugs including contraceptives and tobacco. All of these can alter cortisol or DHEA levels. We looked exclusively at genotype and steroid concentrations, with no noted gender effects. Due to the limited amount of sample DNA, we were not able to sequence the XL alleles to determine the genetic architecture of the VNTRs.

Our allelic distribution was within HWE and verified by our collaborators at CNMC with consistent results. We utilized reagents and methods to compensate for S allele overexpression as previously described [31]. In addition to the common VNTR alleles, a small subpopulation of this AA cohort carried the XL allele. For this study, participants with the XLL genotype had threefold higher mean cortisol and twofold higher DHEAS levels than those with the LL, LS, and SS genotypes. This was also true when classified by functional genotypes. Despite the small sample size of the XLL genotype for both the VNTR and FN groupings, this finding is of interest. Further research is needed to determine if these genotypes are predisposed to maladies associated with dysregulation of the HPA axis and conveying a causal factor for health disparities.

\section{Conclusion}

In summary, whereas the rs 25531 SNP does not appear to be associated with either salivary cortisol or DHEAS levels in AA, people with the XLL genotype had significantly higher levels of salivary cortisol and DHEAS when analyzed by VNTR than the other genotypes. This relationship was maintained when the VNTR and rs25531 SNP polymorphisms were combined to create the FN polymorphism. Based on gene expression, those with the $\mathrm{XLL}_{\mathrm{A}}$ genotype $(n=5)$ again had significantly higher cortisol and DHEAS concentrations than those with the $\mathrm{L}_{\mathrm{A}} \mathrm{L}_{\mathrm{A}}, \mathrm{L}_{\mathrm{A}} \mathrm{S}+$, or $\mathrm{S}+\mathrm{S}+$ genotypes.

\section{Disclaimer}

The views expressed are those of the authors and do not necessarily reflect the official policy or position of the Uniformed Services University, Naval Medical Research Center, Department of the Navy, Department of the Army, or the United States Department of Defense.

\section{Conflict of Interests}

The authors report no conflict of interests.

\section{Acknowledgments}

This research was performed at USUHS. The authors acknowledge that this project was funded by NCMHD, National Institutes of Health, MD, Establishing Exploratory NCMHD Research Centers of Excellence (P20), and RFAMD-07-00.

\section{References}

[1] C. S. Barr, T. K. Newman, S. Lindell et al., "Early experience and sex interact to influence limbic-hypothalamic- pituitaryadrenal-axis function after acute alcohol administration in rhesus macaques (Macaca mulatta)," Alcoholism: Clinical and Experimental Research, vol. 28, no. 7, pp. 1114-1119, 2004.

[2] C. S. Barr, T. K. Newman, C. Shannon et al., "Rearing condition and rh5-HTTLPR interact to influence limbic-hypothalamicpituitary-adrenal axis response to stress in infant macaques," Biological Psychiatry, vol. 55, no. 7, pp. 733-738, 2004.

[3] M. Wankerl, B.-C. Zyriax, B. Bondy, K. Hinkelmann, E. Windler, and C. Otte, "Serotonin transporter gene-linked polymorphic region (5-HTTLPR) and diurnal cortisol: a sex by genotype interaction," Biological Psychology, vol. 85, no. 2, pp. 344-346, 2010.

[4] L. K. Heisler, N. Pronchuk, K. Nonogaki et al., "Serotonin activates the hypothalamic-pituitary-adrenal axis via serotonin $2 \mathrm{C}$ receptor stimulation," The Journal of Neuroscience, vol. 27, no. 26, pp. 6956-6964, 2007.

[5] J. Hoffman, J. Kaplan, B. Kinkead, S. Berga, and M. Wilson, "Metabolic and reproductive consequences of the serotonin transporter promoter polymorphism (5-HTTLPR) in adult female rhesus monkeys (Macaca mulatta)," Endocrine, vol. 31, no. 2, pp. 202-211, 2007.

[6] X. Jiang, J. Wang, T. Luo, and Q. Li, "Impaired hypothalamicpituitary-adrenal axis and its feedback regulation in serotonin transporter knockout mice," Psychoneuroendocrinology, vol. 34, no. 3, pp. 317-331, 2009. 
[7] E. S. Buhl, T. K. Jensen, N. Jessen et al., "Treatment with an SSRI antidepressant restores hippocampo-hypothalamic corticosteroid feedback and reverses insulin resistance in low-birthweight rats," American Journal of Physiology-Endocrinology and Metabolism, vol. 298, no. 5, pp. E920-E929, 2010.

[8] C. Kirschbaum and D. H. Hellhammer, "Salivary cortisol in psychobiological research: an overview," Neuropsychobiology, vol. 22, no. 3, pp. 150-169, 1989.

[9] E. K. Adam and M. R. Gunnar, "Relationship functioning and home and work demands predict individual differences in diurnal cortisol patterns in women," Psychoneuroendocrinology, vol. 26, no. 2, pp. 189-208, 2001.

[10] J. C. Pruessner, O. T. Wolf, D. H. Hellhammer et al., "Free cortisol levels after awakening: a reliable biological marker for the assessment of adrenocortical activity," Life Sciences, vol. 61, no. 26, pp. 2539-2549, 1997.

[11] R. Rosmond and P. Björntorp, "The hypothalamic-pituitaryadrenal axis activity as a predictor of cardiovascular disease, type 2 diabetes and stroke," Journal of Internal Medicine, vol. 247, no. 2, pp. 188-197, 2000.

[12] M. R. Gunnar, S. J. Morison, K. Chisholm, and M. Schuder, "Salivary cortisol levels in children adopted from Romanian orphanages," Development and Psychopathology, vol. 13, no. 3, pp. 611-628, 2001.

[13] M. R. Gunnar and D. M. Vazquez, "Low cortisol and a flattening of expected daytime rhythm: potential indices of risk in human development," Development and Psychopathology, vol. 13, no. 3, pp. 515-538, 2001.

[14] C. M. Ghiciuc, C. L. Cozma-Dima, V. Pasquali et al., "Awakening responses and diurnal fluctuations of salivary cortisol, DHEA-S and alpha-amylase in healthy male subjects," Neuroendocrinology Letters, vol. 32, no. 4, pp. 475-480, 2011.

[15] E. C. Prom-Wormley, T. P. York, K. C. Jacobson et al., "Genetic and environmental effects on diurnal dehydroepiandrosterone sulfate concentrations in middle-aged men," Psychoneuroendocrinology, vol. 36, no. 10, pp. 1441-1452, 2011.

[16] R. H. Straub, J. Schölmerich, and B. Zietz, "Replacement therapy with DHEA plus corticosteroids in patients with chronic inflammatory diseases-substitutes of adrenal and sex hormones," Zeitschrift für Rheumatologie, vol. 59, supplement 2, pp. II108-II118, 2000.

[17] S. Fischli, S. Jenni, S. Allemann et al., "Dehydroepiandrosterone sulfate in the assessment of the hypothalamic-pituitary-adrenal axis," The Journal of Clinical Endocrinology and Metabolism, vol. 93, no. 2, pp. 539-542, 2008.

[18] M. A. Sheridan, J. How, M. Araujo, M. A. Schamberg, and C. A. Nelson, "What are the links between maternal social status, hippocampal function, and HPA axis function in children?" Developmental Science, vol. 16, no. 5, pp. 665-675, 2013.

[19] J. Mouthaan, M. Sijbrandij, J. S. K. Luitse, J. C. Goslings, B. P. R. Gersons, and M. Olff, "The role of acute cortisol and DHEAS in predicting acute and chronic PTSD symptoms," Psychoneuroendocrinology, vol. 45, pp. 179-186, 2014.

[20] G. S. Smith, F. E. Lotrich, A. K. Malhotra et al., "Effects of serotonin transporter promoter polymorphisms on serotonin function," Neuropsychopharmacology, vol. 29, no. 12, pp. 22262234, 2004.

[21] A. Heils, A. Teufel, S. Petri et al., "Allelic variation of human serotonin transporter gene expression," Journal of Neurochemistry, vol. 66, no. 6, pp. 2621-2624, 1996.

[22] D. A. Collier, G. Stöber, T. Li et al., "A novel functional polymorphism within the promoter of the serotonin transporter gene: possible role in susceptibility to affective disorders," Molecular Psychiatry, vol. 1, no. 6, pp. 453-460, 1996.

[23] K.-P. Lesch, D. Bengel, A. Heils et al., "Association of anxietyrelated traits with a polymorphism in the serotonin transporter gene regulatory region," Science, vol. 274, no. 5292, pp. 1527-1531, 1996.

[24] X.-Z. Hu, R. H. Lipsky, G. Zhu et al., "Serotonin transporter promoter gain-of-function genotypes are linked to obsessivecompulsive disorder," The American Journal of Human Genetics, vol. 78, no. 5, pp. 815-826, 2006.

[25] X. Hu, G. Oroszi, J. Chun, T. L. Smith, D. Goldman, and M. A. Schuckit, "An expanded evaluation of the relationship of four alleles to the level of response to alcohol and the alcoholism risk," Alcoholism: Clinical and Experimental Research, vol. 29, no. 1, pp. 8-16, 2005.

[26] C. L. Contreras-Sesvold, N. Sambuughin, A. Blokhin, and P. A. Deuster, "A protocol comparison for the analysis of heat shock protein AlB +A1538G SNP," Cell Stress and Chaperones, vol. 15, no. 2, pp. 205-209, 2010.

[27] D. L. Murphy, M. A. Fox, K. R. Timpano et al., "How the serotonin story is being rewritten by new gene-based discoveries principally related to SLC6A4, the serotonin transporter gene, which functions to influence all cellular serotonin systems," Neuropharmacology, vol. 55, no. 6, pp. 932-960, 2008.

[28] E. A. Ehli, Y. Hu, T. Lengyel-Nelson, J. J. Hudziak, and G. E. Davies, "Identification and functional characterization of three novel alleles for the serotonin transporter-linked polymorphic region," Molecular Psychiatry, vol. 17, no. 2, pp. 185-192, 2012.

[29] N. Alexander, Y. Kuepper, A. Schmitz, R. Osinsky, E. Kozyra, and J. Hennig, "Gene-environment interactions predict cortisol responses after acute stress: Implications for the etiology of depression," Psychoneuroendocrinology, vol. 34, no. 9, pp. 12941303, 2009.

[30] S. Wüst, R. Kumsta, J. Treutlein et al., "Sex-specific association between the 5-HTT gene-linked polymorphic region and basal cortisol secretion," Psychoneuroendocrinology, vol. 34, no. 7, pp. 972-982, 2009.

[31] J. R. Wendland, B. J. Martin, M. R. Kruse, K.-P. Lesch, and D. L. Murphy, "Simultaneous genotyping of four functional loci of human SLC6A4, with a reappraisal of 5-HTTLPR and rs25531," Molecular Psychiatry, vol. 11, no. 3, pp. 224-226, 2006. 


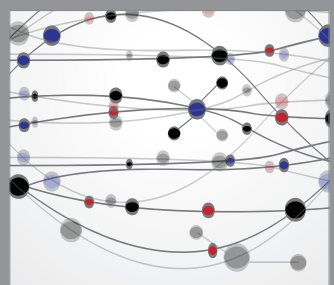

The Scientific World Journal
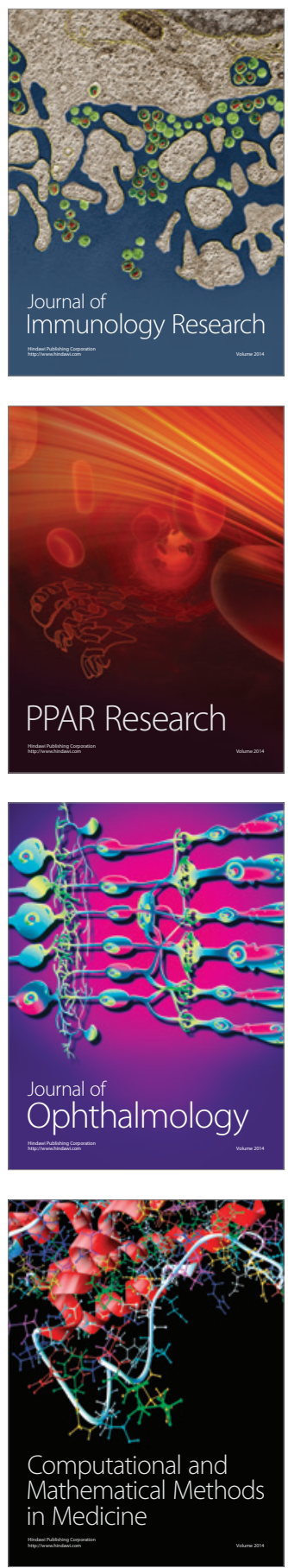

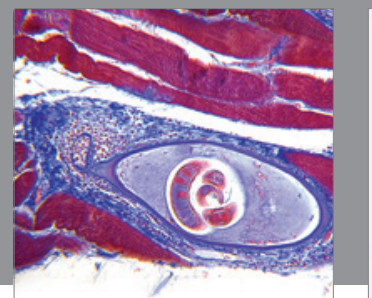

Gastroenterology

Research and Practice
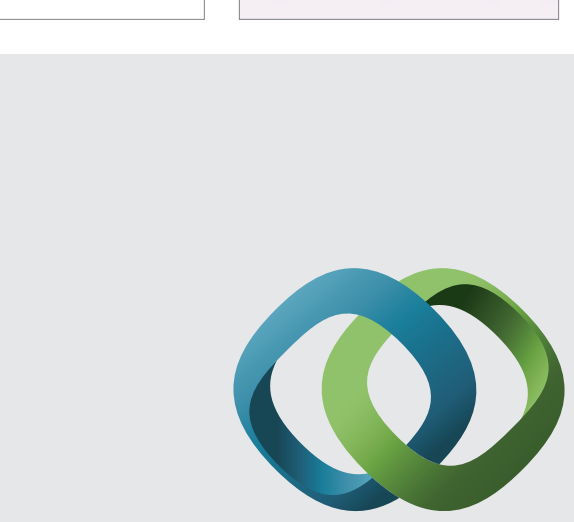

\section{Hindawi}

Submit your manuscripts at

http://www.hindawi.com
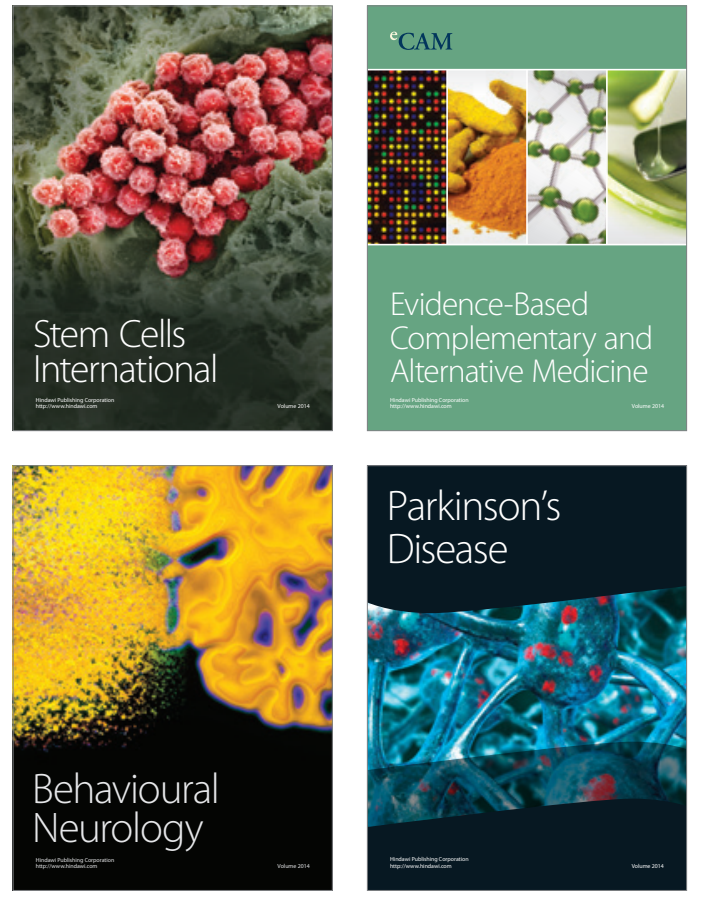
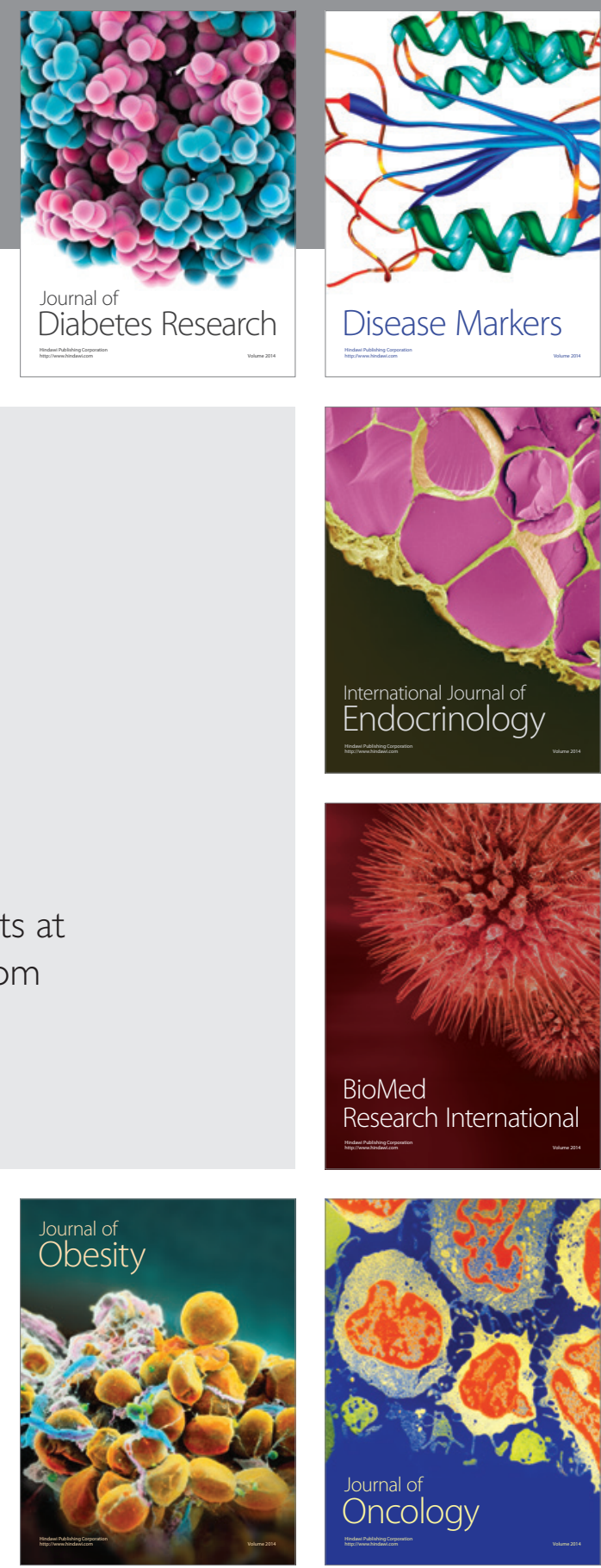

Disease Markers
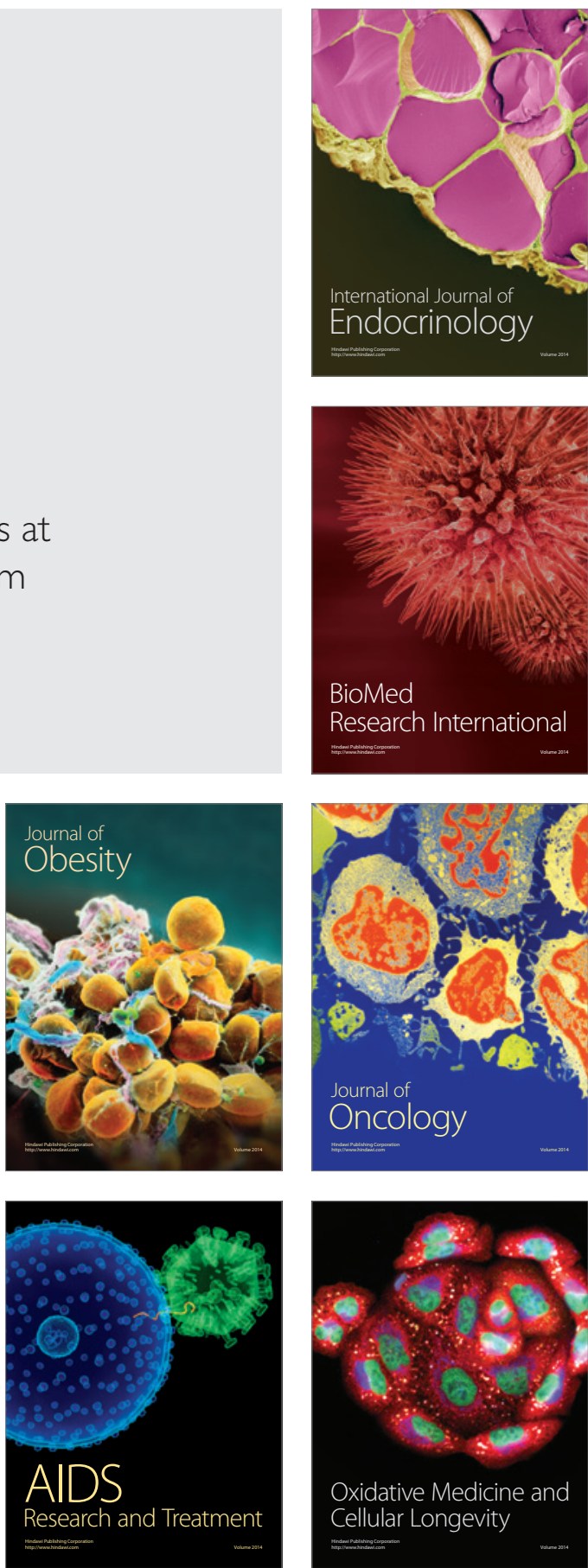